\title{
Komparasi Metode Simple Additive Weighting dan Analytical Hierarchy Process dalam Rekomendasi Penyewaan Pakaian
}

\author{
Erlangga*, Repa Aprilia, Ayu Kartika Puspa, Fenty Ariani \\ Program Sistem Informasi, Fakultas Ilmu Komputer \\ Universitas Bandar Lampung \\ Lampung, INDONESIA \\ erlangga@ubl.ac.id*,repa.18411036@student.ubl.ac.id, ayukartikapuspa@ubl.ac.id, fenty.ariani@ubl.ac.id
}

\begin{abstract}
Clothing is used as a symbol of the wearer's position. This requires people to follow the lifestyle of clothing trends. Clothing trends today change very quickly and tend to be relatively short-lived. As a result of these changes, people are encouraged to become consumptive. Now people can enjoy it without having to buy expensive clothes. Branded clothes can also be used cheaply. Therefore, clothing rental is a stylish yet fashionable option. There are many clothing rentals shops today, but there is no specific information for renters who are looking for a rental shop that fits their needs. People tend to search and visit rental locations to rent clothes. This rental recommendation makes it easier for tenants to find clothes according to their own criteria. The purpose of this study was to compare the SAW-AHP method which was most suitable for the case of this study. After calculating and comparing the two methods, the SAW method is suitable for this case because it can count all samples, while the AHP method can only count 15 samples according to the Random Index table.
\end{abstract}

Keywords: Comparison; DSS; AHP; SAW; Clothing Rental Recommendations.

\begin{abstract}
Abstrak - Pakaian digunakan sebagai simbol kedudukan pemakainya. Hal ini menuntut masyarakat untuk mengikuti gaya hidup trend pakaian. Tren pakaian saat ini berubah sangat cepat dan cenderung relatif singkat. Akibat perubahan tersebut, masyarakat terdorong untuk menjadi konsumtif. Kini masyarakat dapat menikmatinya tanpa harus membeli baju mahal. Pakaian bermerek juga dapat digunakan dengan biaya murah. Oleh karena itu, persewaan pakaian adalah pilihan yang stylish namun tetap modis. Ada banyak toko persewaan pakaian saat ini, tetapi tidak ada informasi khusus bagi penyewa yang mencari toko persewaan yang sesuai dengan kebutuhan mereka. Orang cenderung mencari dan mengunjungi lokasi persewaan untuk menyewa pakaian. Rekomendasi sewa ini memudahkan penyewa untuk mencari pakaian sesuai dengan kriterianya sendiri. Tujuan dari penelitian ini adalah untuk membandingkan metode SAW-AHP yang paling sesuai untuk kasus penelitian ini. Setelah menghitung dan membandingkan kedua metode tersebut maka metode SAW cocok untuk kasus ini karena dapat menghitung semua sampel, sedangkan metode AHP hanya dapat menghitung 15 sampel menurut tabel Random Index.
\end{abstract}

Kata Kunci: Komparasi; SPK; AHP; SAW; Rekomendasi Penyewaan Pakaian.

\section{Pendahuluan}

Dengan berkembangnya kehidupan manusia, pakaian digunakan sebagai simbol, jabatan, kedudukan atau status dari orang yang memakainya. Pada tahun 2020, Indonesia dinyatakan sebagai benchmark fashion Islam dunia [1]. Hal tersebut menuntut masyarakat untuk mengikuti gaya hidup trend pakaian. Tren pakaian saat ini sangat cepat mengalami perubahan dan cendrung relatif singkat. Akibat dari perubahan tersebut masyarakat terdorong untuk berperilaku konsumtif. Tren konsumtif cenderung mengeluarkan biaya yang cukup banyak, pasalnya trend konsumtif bukan hanya memenuhi kebutuhan saja tetapi cenderung kepada pemenuhan keinginan.

Pakaian merupakan alat komunikasi yang penting. Pesan yang disampaikan pakaian tergantung pada banyak faktor, termasuk pengalaman dan latar belakang budaya.
Pakaian adalah ekspresi dan identitas seseorang. Karena memilih baju di toko atau di rumah berarti mendefinisikan dan menjelaskan diri sendiri [2]. Sebesar $42.42 \%$ barang dibeli tanpa terencana adalah pakaian [1]. Pakaian yang mahal kini bisa dinikmati tanpa harus membelinya. Baju brended pun bisa digunakan dengan biaya yang lebih murah. Sehingga penyewaan pakaian menjadi opsi untuk bergaya namun tetap modis. Di Indonesia tempat-tempat penyewaan sudah sangat banyak lebih lagi jika hari-hari besar datang. Permasalahan-permasalahan pun muncul dari konsumen penyewaan pakaian diantaranya adalah minimnya informasi lokasi atau tempat penyewaan yang ada [3], masyarakat harus mendatangi beberapa tempat penyewaan untuk menyewa pakaian yang diinginkan [4].

Sewa sendiri merupakan perjanjian untuk menggunakan sesuatu untuk sementara waktu (untuk jangka waktu tertentu) dengan harga tertentu. Dalam 
sewa, pemilik properti berjanji untuk menggunakan hanya hasil dari sewa properti, dan kepemilikan properti sepenuhnya dimiliki oleh orang yang memiliki properti. [5].

Semakin merebaknya fashion store yang bermunculan, semakin sulit bagi konsumen untuk menentukan fashion store mana yang memenuhi kriteria yang dipersyaratkan. Oleh karena itu, tujuan dari penelitian ini adalah untuk memberikan pedoman bagi fashion store agar dapat dengan mudah diidentifikasi. Hal ini bertujuan untuk mengarahkan konsumen saat membeli atau menyewa produk tertentu berdasarkan penilaian yang diberikan oleh konsumen lain. Maka dibutuhkan sebuah sistem rekomendasi rental, dan berfungsi untuk memprediksi barang yang diinginkan oleh pengguna [6]. Internet memiliki kemampuan untuk melakukan aktivitas seperti pemasaran produk online yang memerlukan koneksi internet. Hal ini dikenal sebagai e-marketing, e-marketing untuk membantu perusahaan, pelanggan, dan mitra bisnis melakukan transaksi. Permasalahan yang ditemukan adalah kurangnya pengembangan e-marketing yang sebagian besar masih menggunakan cara pemasaran yang kuno atau tradisional [7].

Sistem rekomendasi sendiri merupakan sistem yang dapat memberikan rekomendasi kepada pelanggan berdasarkan kriteria yang ada [8]. Sistem rekomendasi ini diperlukan untuk memudahkan masyarakat dalam memilih tempat persewaan terbaik. Penelitian ini akan menghitung sistem rekomendasi penyewaan pakaian yang memenuhi kriteria yang diinginkan. Salah satu metode yang tersedia untuk sistem rekomendasi persewaan pakaian adalah metode Simple Additive Weighing ( $S A W)$ dan metode Analytic Hierarchy Process (AHP). Penggunaan metode AHP ini untuk menentukan bobot dan metode SAW untuk menentukan peringkat terbaik. Metode AHP adalah model pengambilan keputusan yang canggih yang tidak hanya mempercepat dan menyederhanakan proses, tetapi juga memecahkan masalah menjadi beberapa bagian dan mengaturnya secara hierarkis [9]. Konsep dasar SAW adalah mencari jumlah bobot dari setiap kriteria untuk setiap alternatif untuk menentukan alternatif mana yang memiliki rating tertinggi.

Beberapa penelitian sebelumnya menunjukkan bahwa metode SAW-AHP dapat digunakan untuk merekomendasikan properti [10]. Metode SAW-AHP juga dapat meminimalisir adanya $\mathrm{KKN}$ dengan menggunakan sistem pendukung keputusan untuk mengamankan status pegawai [9].

Menanggapi kekhawatiran yang ada, penelitian ini menganalisis mode dan merekomendasikan penyewaan pakaian untuk mengurangi biaya sewa pakaian dan memfasilitasi penyewaan pakaian melalui sistem rekomendasi. Tentunya dalam menyewa pakaian diperlukan kriteria tertentu seperti jenis, ukuran, kualitas, dan lokasi pakaian. Tujuan dari penelitian ini adalah menyajikan rekomendasi persewaan pakaian dengan metode SAW-AHP, membandingkan metode SAWAHP, dan menilai kedua metode menggunakan metode SAW-AHP.

\section{Metodologi}

Metode pengumpulan data yang digunakan dalam penelitian ini meliputi studi kepustakaan dan kuesioner. Studi kepustakaan itu sendiri adalah segala upaya yang bertujuan untuk mengumpulkan data yang berkaitan dengan pokok bahasan atau masalah yang sedang dipelajari atau dipelajari. Informasi untuk penelitian ini diperoleh dari jurnal, buku ilmiah, laporan penelitian, kerangka ilmiah, dan sumber tertulis dan cetak lainnya. Kuisioner adalah alat penilaian yang paling populer karena menghemat waktu, membutuhkan keahlian, dan mudah digunakan. Kuisioner [11] juga merupakan metode pengumpulan data utama sebagai metode survei untuk mengkonfirmasi pendapat responden.

\section{Hasil dan Pembahasan}

\section{A. Implementasi Metode SAW}

Langkah-langkah perhitungan dengan metode SAW: (1) menentukan kriteria pengambilan keputusan; (2) penentuan bobot kriteria dengan metode AHP; (3) Menentukan peringkat kesesuaian setiap alternatif untuk setiap kriteria dalam metode SAW. (4) Membuat matriks keputusan sesuai dengan kriteria. Kemudian kita menormalkan matriks persamaan yang ditetapkan berdasarkan jenis atribut (atribut manfaat atau atribut biaya) untuk mendapatkan matriks yang dinormalisasi. (5) Hasil yang diperoleh pada proses rangking adalah vektor bobot ditambah perkalian matriks ternormalisasi, sehingga dipilih nilai terbesar sebagai alternatif terbaik sebagai solusi.

Langkah-langkah pengintegrasian metode SAW ke dalam pedoman sewa pakaian pada penelitian ini ditunjukkan pada Gambar 1.

Kriteria yang digunakan dalam rekomendasi penyewaan pakaian untuk memutuskan toko mana yang akan terseleksi sebagai toko terbaik menggunakan metode SAW ini yaitu menggunakan 6 kriteria, Tabel 1.

Dalam proses pemeringkatan rekomendasi toko persewaan pakaian terbaik, data yang dibutuhkan adalah alternatif-alternatif yang dapat dijadikan acuan dalam pengambilan keputusan yaitu toko persewaan pakaian, penilaian kesesuaian untuk setiap alternatif dan kriteria, serta bobot kepentingan.

Output yang dihasilkan mencakup alternatifalternatif dengan nilai tertinggi relatif terhadap yang lain. Hasilnya adalah peringkat posisi tertentu diambil secara berurutan dari yang tertinggi hingga yang terendah. Alternatif yang digunakan adalah 25 tempat persewaan baju., Tabel 2.

Data aktual akan digunakan sebagai skala perbandingan seperti yang dijelaskan di atas, nilai MIN adalah biaya (cost) karena semakin rendah angka semakin baik, jika nilai MAX merupakan keuntungan (benefit) karena semakin tinggi semakin baik., Tabel 3.

Tahap normalisasi didapat dari membagi $X i j$ atau setiap baris dengan nilai maximun jika nilai bersifat benefit. Jika bersifat cost maka nilai minimum dibagi dengan Xij. Normalisasi didapat dari membagi nilai 
terkecil dibagi dengan nilai setiap kriteria jika bersifat cost. Membagi nilai setiap kriteria dengan nilai yang paling besar jika bersifat benefit. Akan bersifat max jika benefit dan akan bersifat min jika benefit. Impementasi rumus normalisasi metode SAW dengan Rumus (1) sehingga $r_{i j}\left\{\begin{array}{l}\frac{x_{i j}}{M A X_{I}\left(x_{i j}\right)} \\ \frac{M I N_{i}\left(x_{i j}\right)}{x_{i j}}\end{array}\right.$ diperoleh Tabel 4.

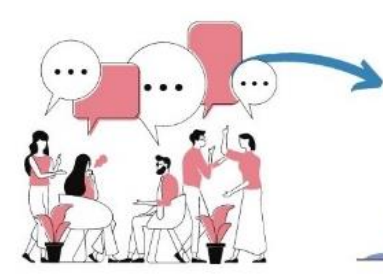

(1) Penentuan Masalah

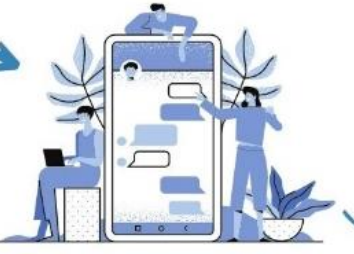

(2)

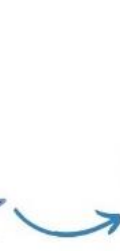

(3)

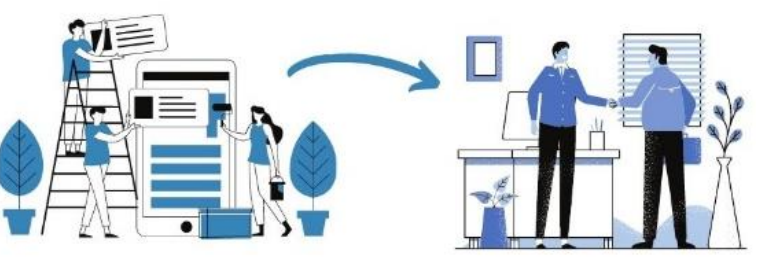

3) (4)

Pemberian Nilai Bobot pada tiap Kriteria
Pemberian Nilai Alternatif pada Kriteria

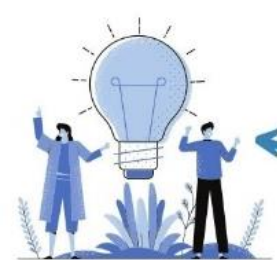

(8)

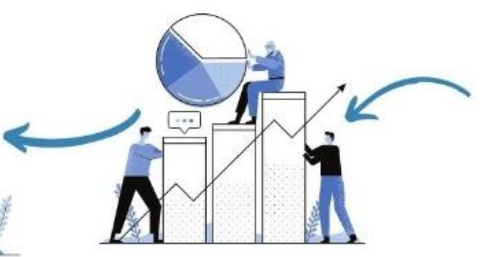

(7) Menghitung Nilai Bobot Preferensi

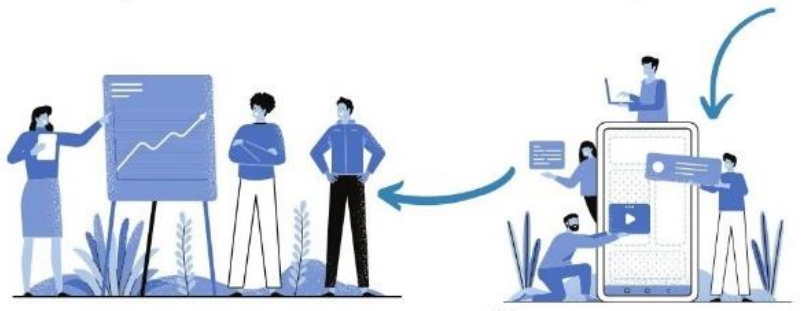

(6)

Pembuatan Matriks Nilai
(5)

Menghitung Normalisasi tiap Alternatif

Gambar 1. Diagram Alur Penyelesaian Metode SAW [12]

Tabel 1. Kriteria Penentu Rekomendasi Penyewaan Pakaian

\begin{tabular}{|c|c|c|c|c|c|c|c|}
\hline No & Kriteria & Kode & Bobot & Atribut & Indikator & Nilai & Keterangan \\
\hline \multirow[t]{4}{*}{1} & Harga Sewa & HS & 0.16 & Cost & $\geq$ Rp. 500.000 .00 & 1 & Kurang \\
\hline & & & & & Rp. 300.000 .00 - Rp. 499.000 .00 & 2 & Cukup \\
\hline & & & & & Rp. 100.000 .00 - Rp. 299.000 .00 & 3 & Baik \\
\hline & & & & & $\leq$ Rp. 100.000 .00 & 4 & Sangat Baik \\
\hline \multirow[t]{4}{*}{2} & Kualitas Bahan & $\mathrm{KB}$ & 0.26 & Benefit & KW Super & 1 & Kurang \\
\hline & & & & & KW & 2 & Cukup \\
\hline & & & & & Premium & 3 & Baik \\
\hline & & & & & Original & 4 & Sangat Baik \\
\hline \multirow[t]{4}{*}{3} & Kelengkapan & $\mathrm{KP}$ & 0.13 & Benefit & $\leq 5$ Aksesoris & 1 & Kurang \\
\hline & Pakaian & & & & $6-10$ Aksesoris & 2 & Cukup \\
\hline & & & & & $11-15$ Aksesoris & 3 & Baik \\
\hline & & & & & $\geq 16$ Aksesoris & 4 & Sangat Baik \\
\hline \multirow[t]{4}{*}{4} & Jarak Lokasi & JL & 0.07 & Cost & $\geq 7$ Kilometer & 1 & Kurang \\
\hline & & & & & $5-6$ Kilometer & 2 & Cukup \\
\hline & & & & & $2-4$ Kilometer & 3 & Baik \\
\hline & & & & & $\leq 1$ Kilometer & 4 & Sangat Baik \\
\hline \multirow[t]{4}{*}{5} & Lama Sewa & LS & 0.07 & Benefit & $\leq 2$ Hari & 1 & Kurang \\
\hline & & & & & $3-4$ Hari & 2 & Cukup \\
\hline & & & & & $5-6$ Hari & 3 & Baik \\
\hline & & & & & $\geq 7$ Hari & 4 & Sangat Baik \\
\hline \multirow[t]{4}{*}{6} & Jenis Pakaian & JP & 0.32 & Benefit & $\leq 10$ Jenis & 1 & Kurang \\
\hline & & & & & $10-20$ Jenis & 2 & Cukup \\
\hline & & & & & $21-30$ Jenis & 3 & Baik \\
\hline & & & & & $\geq 31$ Jenis & 4 & Sangat Baik \\
\hline
\end{tabular}


Tabel 2. Data Kriteria Alternatif

\begin{tabular}{lrlcccc}
\hline Alternatif (TS) & HS (Rupiah) & KB & KP (Aksesoris) & JL (Kilometer) & LS (Hari) & JP (Jenis) \\
\hline Toko Sewa 1 & 150.000 & Premium & 16 & 5 & 3 & 35 \\
Toko Sewa 2 & 99.000 & Kw & 5 & 1 & 5 & 15 \\
Toko Sewa 3 & 650.000 & Premium & 19 & 1 & 4 & 31 \\
Toko Sewa 4 & 200.000 & Kw Super & 8 & 7 & 6 & 25 \\
Toko Sewa 5 & 350.000 & Premium & 7 & 8 & 4 & 17 \\
Toko Sewa 6 & 250.000 & Kw & 14 & 3 & 5 & 18 \\
Toko Sewa 7 & 400.000 & Kw & 9 & 1 & 5 & 25 \\
Toko Sewa 8 & 340.000 & Kw & 5 & 5 & 8 & 11 \\
Toko Sewa 9 & 200.000 & Premium & 5 & 3 & 5 & 22 \\
Toko Sewa 10 & 300.000 & Premium & 19 & 1 & 7 & 19 \\
Toko Sewa 11 & 260.000 & Premium & 7 & 3 & 6 & 26 \\
Toko Sewa 12 & 150.000 & Kw & 7 & 4 & 5 & 7 \\
Toko Sewa 13 & 95.000 & Premium & 8 & 2 & 6 & 39 \\
Toko Sewa 14 & 80.000 & Kw Super & 9 & 4 & 2 & 18 \\
Toko Sewa 15 & 360.000 & Original & 11 & 5 & 6 & 33 \\
Toko Sewa 16 & 320.000 & Premium & 19 & 4 & 4 & 24 \\
Toko Sewa 17 & 85.000 & Premium & 12 & 6 & 5 & 27 \\
Toko Sewa 18 & 90.000 & Kw & 7 & 1 & 6 & 25 \\
Toko Sewa 19 & 300.000 & Original & 5 & 8 & 8 & 6 \\
Toko Sewa 20 & 99.000 & Kw Super & 14 & 1 & 2 & 23 \\
Toko Sewa 21 & 500.000 & Original & 5 & 3 & 4 & 14 \\
Toko Sewa 22 & 240.000 & Premium & 5 & 4 & 5 & 15 \\
Toko Sewa 23 & 280.000 & Kw Super & 5 & 4 & 1 & 16 \\
Toko Sewa 24 & 550.000 & Original & 14 & 4 & 2 & 33 \\
Toko Sewa 25 & 200.000 & Premium & 7 & 6 & 3 & 7 \\
\hline
\end{tabular}

Tabel 3. Nilai Rating Kecocokan Kriteria Alternatif

\begin{tabular}{lcccccc}
\hline Alternatif & HS & KB & KP & JL & LS & JP \\
\hline TS1 & 3 & 3 & 4 & 2 & 1 & 3 \\
TS2 & 4 & 2 & 1 & 4 & 3 & 2 \\
TS3 & 1 & 3 & 4 & 4 & 3 & 4 \\
TS4 & 3 & 1 & 2 & 1 & 4 & 3 \\
TS5 & 2 & 3 & 2 & 1 & 3 & 2 \\
TS6 & 3 & 2 & 3 & 3 & 3 & 2 \\
TS7 & 2 & 2 & 2 & 4 & 3 & 3 \\
TS8 & 2 & 2 & 1 & 2 & 4 & 2 \\
TS9 & 3 & 3 & 1 & 3 & 3 & 3 \\
TS10 & 2 & 3 & 4 & 3 & 4 & 2 \\
TS11 & 2 & 3 & 2 & 4 & 3 & 3 \\
TS12 & 3 & 2 & 2 & 2 & 3 & 1 \\
TS13 & 4 & 3 & 2 & 3 & 3 & 4 \\
TS14 & 4 & 1 & 2 & 4 & 1 & 2 \\
TS15 & 2 & 4 & 3 & 2 & 3 & 4 \\
TS16 & 2 & 3 & 4 & 1 & 2 & 3 \\
TS17 & 4 & 3 & 3 & 2 & 3 & 3 \\
TS18 & 4 & 2 & 2 & 4 & 3 & 3 \\
TS19 & 2 & 4 & 1 & 1 & 4 & 1 \\
TS20 & 4 & 1 & 3 & 4 & 2 & 3 \\
TS21 & 1 & 4 & 1 & 3 & 2 & 2 \\
TS22 & 3 & 3 & 1 & 1 & 3 & 2 \\
TS23 & 3 & 1 & 1 & 3 & 1 & 2 \\
TS24 & 1 & 4 & 3 & 1 & 1 & 4 \\
TS25 & 3 & 3 & 2 & 2 & 2 & 1 \\
\hline Nilai Max Min & 1 & 4 & 4 & 1 & 4 & 4 \\
\cline { 2 - 7 } & Min & Max & Max & Min & Max & Max \\
\hline & & & & & &
\end{tabular}


Tabel 4. Hasil Normalisasi dengan Metode SAW

\begin{tabular}{lcccccc}
\hline Alternatif & HS & KB & KP & JL & LS & JP \\
\hline TS1 & 0.33 & 0.75 & 1.00 & 0.50 & 0.25 & 0.75 \\
TS2 & 0.25 & 0.50 & 0.25 & 0.25 & 0.75 & 0.50 \\
TS3 & 1.00 & 0.75 & 1.00 & 0.25 & 0.75 & 1.00 \\
TS4 & 0.33 & 0.25 & 0.50 & 1.00 & 1.00 & 0.75 \\
TS5 & 0.50 & 0.75 & 0.50 & 1.00 & 0.75 & 0.50 \\
TS6 & 0.33 & 0.50 & 0.75 & 0.33 & 0.75 & 0.50 \\
TS7 & 0.50 & 0.50 & 0.50 & 0.25 & 0.75 & 0.75 \\
TS8 & 0.50 & 0.50 & 0.25 & 0.50 & 1.00 & 0.50 \\
TS9 & 0.33 & 0.75 & 0.25 & 0.33 & 0.75 & 0.75 \\
TS10 & 0.50 & 0.75 & 1.00 & 0.33 & 1.00 & 0.50 \\
TS11 & 0.50 & 0.75 & 0.50 & 0.25 & 0.75 & 0.75 \\
TS12 & 0.33 & 0.50 & 0.50 & 0.50 & 0.75 & 0.25 \\
TS13 & 0.25 & 0.75 & 0.50 & 0.33 & 0.75 & 1.00 \\
TS14 & 0.25 & 0.25 & 0.50 & 0.25 & 0.25 & 0.50 \\
TS15 & 0.50 & 1.00 & 0.75 & 0.50 & 0.75 & 1.00 \\
TS16 & 0.50 & 0.75 & 1.00 & 1.00 & 0.50 & 0.75 \\
TS17 & 0.25 & 0.75 & 0.75 & 0.50 & 0.75 & 0.75 \\
TS18 & 0.25 & 0.50 & 0.50 & 0.25 & 0.75 & 0.75 \\
TS19 & 0.50 & 1.00 & 0.25 & 1.00 & 1.00 & 0.25 \\
TS20 & 0.25 & 0.25 & 0.75 & 0.25 & 0.50 & 0.75 \\
TS21 & 1.00 & 1.00 & 0.25 & 0.33 & 0.50 & 0.50 \\
TS22 & 0.33 & 0.75 & 0.25 & 1.00 & 0.75 & 0.50 \\
TS23 & 0.33 & 0.25 & 0.25 & 0.33 & 0.25 & 0.50 \\
TS24 & 1.00 & 1.00 & 0.75 & 1.00 & 0.25 & 1.00 \\
TS25 & 0.33 & 0.75 & 0.50 & 0.50 & 0.50 & 0.25 \\
\hline & & & & & &
\end{tabular}

Peringkat toko terbaik dihitung dengan mengalikan setiap bobot kriteria yang telah dihitung dengan metode AHP dengan masing-masing nilai yang dinormalisasi dan dijumlahkan semuanya dan mendapatkan nilai pilihan (preference) atau skor akhir. Angka apa pun yang lebih besar atau lebih besar akan menentukan toko yang direkomendasikan terbaik.

\section{B. Implementasi Metode AHP}

Langkah-langkah metode AHP: (1) Melakukan perbandingan berpasangan. Perbandingan dilakukan dengan mengevaluasi pentingnya suatu kriteria dibandingkan dengan kriteria lainnya sesuai dengan pilihan pengambil keputusan. (2) menormalkan data dengan membagi nilai setiap kriteria ke dalam matriks yang dipasangkan dengan nilai total di setiap kolom, dan (3) memastikan konsistensi hierarki. Jika persyaratan CR $\leq 0.1$ tidak terpenuhi, maka evaluasi harus diulang. (4) Peringkat semua faktor dan kriteria.

Langkah-langkah implementasi metode AHP dalam rekomendasi penyewaan pakaian pada penelitian ini yaitu (1) Menghitung semua kriteria yang sudah tertera akan dihitung menggunakan metode AHP yang kemudian akan diukur konsistensi rasio apakah pembobotan melebihi rasio atau bisa dikatakan bahwa pembobotan harus diubah nialinya atau rasio dianggap konsisten, (2) Menentukan perbandingan berpasangan intensitas kepentingan untuk kriteria, (3) Menentukan perbandingan berpasangan dengan nilai kepentingan yang telah di tentukan.
Nilai Tabel 5 didapat dari skala perbandingan metode AHP, skala perbandingannya yaitu Angka 1 Equal importance (sama penting), Angka 3 Weak importance of one over (sedikit lebih penting) memilih satu kriteria dibandingkan dengan pasangannya, Angka 5 Essential or strong importance (lebih penting) Satu elemen sangat disukai dan secara praktis dominasinya sangat nyata, dibandingkan dengan elemen pasangannya, Angka 7 Demonstrated importance (sangat penting) Satu elemen sangat penting dan secara praktis dominan sangat, dibandingkan dengan elemen pasangannya, Angka 9 Ekstreme importance (mutlak lebih penting) Satu kriteria mutlak lebih penting dibandingkan dengan pasangannya, pada tingkat keyakinan tertinggi. Angka 2, 4, 6, 8 Intermediate values berween the two adjacent judments Nilai diantara dua pilihan yang Berdekatan Respirokal, Kebalikan. Menyederhanakannya menjadi angka decimal dengan menambahkan 2 angka di belakang koma, agar memudahkan perhitungan, Tabel 6 .

Nilai Eigen didapat dari normalisasi matriks dengan cara membagi masing-masing nilai kolom dengan total kolom yang bersangkutan, Tabel 7 .

Selanjutnya adalah mengukur konsistensi rasio. Dalam metode AHP diperlukan rasio konsistensi agar di peroleh keputusan untuk mendekati data valid. Rasio konsistensi harus $\leq 0,1$ atau $10 \%$. Mencari nilai $\lambda$ maksimum dengan mengalikan jumlah setiap baris kriteria dengan setiap rata-rata normalisasi. 


\section{Perbandingan Metode SAW dan Metode AHP}

Berdasarkan Tabel 8 hasil penelitian ini disimpulkan bahwa menggunakan metode SAW lebih cocok untuk kasus analisis perbandingan metode SAW - AHP untuk sistem rekomendasi penyewaan pakaian ini. Karena dengan metode SAW semua elemen atau sampel dapat dihitung dan dirangkingkan, sedangkan dengan metode
AHP elemen atau sampel terbatas sesuai dengan nilai Random Index yaitu sebanyak 15 elemen, nilai Random Index dihitung untuk memastikan tingkat konsistensi pengambilan keputusan saat mengisi nilai perbandingan antara sepasang objek, banyaknya nilai perbandingan adalah sebanyak 15 sampel itulah alasan mengapa metode AHP diatas hanya memakai 15 toko saja.

Tabel 5. Pembobotan Hirarki Kriteria

\begin{tabular}{lcccccc}
\hline Kriteria & HS & KB & KP & JL & LS & JP \\
\hline HS & 1 & $1 / 2$ & 3 & 2 & 2 & $1 / 2$ \\
KB & 2 & 1 & 3 & 4 & 5 & $1 / 2$ \\
KP & $1 / 3$ & $1 / 3$ & 1 & 3 & 4 & $1 / 3$ \\
JL & $1 / 2$ & $1 / 4$ & $1 / 3$ & 1 & 2 & $1 / 4$ \\
LS & $1 / 2$ & $1 / 4$ & $1 / 4$ & $1 / 2$ & 1 & $1 / 4$ \\
JP & 2 & 2 & 3 & 4 & 4 & 1 \\
\hline Jumlah & 6.33 & 4.33 & 10.58 & 14.50 & 18.00 & 2.83 \\
\hline
\end{tabular}

Tabel 6. Faktor Pembobotan Hirarki Kriteria yang Disederhanakan

\begin{tabular}{lcccccc}
\hline Kriteria & HS & KB & KP & JL & LS & JP \\
\hline HS & 1.00 & 0.50 & 3.00 & 2.00 & 2.00 & 0.50 \\
KB & 2.00 & 1.00 & 3.00 & 4.00 & 5.00 & 0.50 \\
KP & 0.33 & 0.33 & 1.00 & 3.00 & 4.00 & 0.33 \\
JL & 0.50 & 0.25 & 0.33 & 1.00 & 2.00 & 0.25 \\
LS & 0.50 & 0.25 & 0.25 & 0.50 & 1.00 & 0.25 \\
JP & 2.00 & 2.00 & 3.00 & 4.00 & 4.00 & 1.00 \\
\hline Jumlah & 6.33 & 4.33 & 10.58 & 14.50 & 18.00 & 2.83 \\
\hline
\end{tabular}

Tabel 7. Nilai Eigen

\begin{tabular}{cccccccc}
\hline \multicolumn{1}{c}{ Nilai Eigen } & & Jumlah & Rata-Rata \\
\hline 0.16 & 0.12 & 0.28 & 0.14 & 0.11 & 0.18 & 0.98 & 0.16 \\
0.32 & 0.23 & 0.28 & 0.28 & 0.28 & 0.18 & 1.56 & 0.26 \\
0.05 & 0.08 & 0.09 & 0.21 & 0.22 & 0.12 & 0.77 & 0.13 \\
0.08 & 0.06 & 0.03 & 0.07 & 0.11 & 0.09 & 0.44 & 0.07 \\
0.08 & 0.06 & 0.02 & 0.03 & 0.06 & 0.09 & 0.34 & 0.06 \\
0.32 & 0.46 & 0.28 & 0.28 & 0.22 & 0.35 & 1.91 & 0.32 \\
\hline
\end{tabular}

Tabel 8. Perbandingan Metode SAW - AHP Rekomendasi Penyewaan Pakaian

\begin{tabular}{lcclcc}
\hline \multicolumn{3}{c}{ HASIL METODE SAW } & \multicolumn{3}{c}{ HASIL METODE AHP } \\
\hline Alternatif & Preferences & Rangking & Alternatif & Preferences & Rangking \\
\hline TS1 & 0.67 & 6 & TS1 & 0.08 & 3 \\
TS2 & 0.43 & 22 & TS2 & 0.06 & 7 \\
TS3 & 0.87 & 2 & TS3 & 0.07 & 5 \\
TS4 & 0.56 & 16 & TS4 & 0.05 & 10 \\
TS5 & 0.62 & 11 & TS5 & 0.05 & 13 \\
TS6 & 0.51 & 18 & TS6 & 0.05 & 11 \\
TS7 & 0.58 & 14 & TS7 & 0.06 & 8 \\
TS8 & 0.50 & 19 & TS8 & 0.05 & 14 \\
TS9 & 0.59 & 12 & TS9 & 0.06 & 9 \\
TS10 & 0.65 & 9 & TS10 & 0.07 & 6 \\
TS11 & 0.64 & 10 & TS11 & 0.07 & 4 \\
TS12 & 0.41 & 23 & TS12 & 0.05 & 12 \\
TS13 & 0.69 & 5 & TS13 & 0.09 & 2 \\
TS14 & 0.36 & 24 & TS14 & 0.04 & 15 \\
TS15 & 0.84 & 3 & TS15 & 0.26 & 1 \\
TS16 & 0.75 & 4 & & & \\
TS17 & 0.65 & 8 & & & \\
\hline
\end{tabular}




\begin{tabular}{lccccc}
\hline \multicolumn{3}{c}{ HASIL METODE SAW } & \multicolumn{3}{c}{ HASIL METODE AHP } \\
\hline Alternatif & Preferences & Rangking & Alternatif & Preferences & Rangking \\
\hline TS18 & 0.54 & 17 & & & \\
TS19 & 0.59 & 13 & & & \\
TS20 & 0.49 & 20 & & & \\
TS21 & 0.67 & 7 & & & \\
TS22 & 0.56 & 15 & & & \\
TS23 & 0.35 & 25 & & & \\
TS24 & 0.93 & 1 & & & \\
TS25 & 0.46 & 21 & & & \\
\hline
\end{tabular}

\section{Kesimpulan}

Dari hasil analisis hasil penelitian ini sesuai dengan metode yang dipilih untuk menentukan toko yang optimal dengan mengakumulasi nilai-nilai yang ada, disimpulkan bahwa rekomendasi toko pakaian memenuhi kriteria sehingga memudahkan pekerjaan. Dalam kasus metode SAW, toko-toko diurutkan dari atas ke bawah untuk memilih toko sewa yang diinginkan, dan dalam kasus rekomendasi ini, metode SAW ditemukan lebih cocok.

\section{Daftar Pustaka}

[1] M. Saufi, "Perancangan Aplikasi Penyewaan Baju Perempuan Berbasis Android (Rent A Dress Apps)," vol. 2, pp. 227-249, 2018.

[2] N. Lisdiantini, "Epicheirisi : Jurnal Manajemen, Administrasi, Pemasaran dan Kesekretariatan Volume 3 Nomor 1 Tahun 2019," vol. 3, pp. 9-15, 2019.

[3] P. Nicolas, P. Studi, S. Informasi, and U. D. Ali, "Sistem Informasi E-Marketplace Penyewaan dan Penjualan Perlengkapan Kostum Ceremonial Di Kota Sampit Berbasis Web 1,2," vol. 10, no. 2, 2019.

[4] D. Berliani, "Sistem Informasi Penggunaan Jasa Makeup dan Penyewaan Busana pada Salon Kecantikan 2d Berbasis Mobile Web.”

[5] R. S. Harahap, A. Yahanan, and S. Handayani, Perlindungan Hukum Pemilik Kamera dalam Perjanjian Sewa-Menyewa dengan Penawaran Online. 2021.
[6] E. Erlangga and H. Sutrisno, "Sistem Rekomendasi Beauty Shop Berbasis Collaborative Filtering," Expert J. Manaj. Sist. Inf. dan Teknol., vol. 10, no. 2, p. 47, 2020, doi: 10.36448/jmsit.v10i2.1611.

[7] E. Erlangga, M. H. Anggraini, F. Ariani, and Y. Aprilinda, "Aplikasi E-Marketing Panglong Kayu Menggunakan Metode Colaborative Filtering," Explor. J. Sist. Inf. dan Telemat., vol. 11, no. 1, pp. 57-66, 2020, doi: 10.36448/jsit.v11i1.1460.

[8] S. N. Rochmawati and F. Marisa, "Sistem Rekomendasi Rumah Berbasis Web Menggunakan Metode SAW pada PT.Inproperty," JOINTECS Journal Inf. Technol. Comput. Sci., vol. 3, no. 2, pp. 95-98, 2018, doi: 10.31328/jointecs.v3i2.808.

[9] D. A. Permatasari, "Penerapan Metode AHP dan SAW untuk Penentuan Kenaikan Jabatan Karyawan,” vol. 5, no. 1, pp. 60-73, 2018.

[10] S. A. Putra, N. Hidayat, and L. Muflikhah, "Rekomendasi Pemilihan Properti Kota Malang Menggunakan Metode," vol. 1, no. 10, pp. 12011209, 2017.

[11] K. Jaya, I. N. Saputra, and W. Wijaya, "Pengembangan Sistem Evaluasi Kinerja Dosen (E-Kuesioner) STMIK STIKOM Indonesia," vol. 8, no. 1, 2019.

[12] E. Erlangga, Y. Yolandari, T. Thamrin, and A. K. Puspa, "Analisis Penerapan Metode Simple Additive Weighting (SAW) Pemilihan Tanaman Hias," Explor. Sist. Inf. dan Telemat., vol. 12, no. 1, p. 56, 2021, doi: 10.36448/jsit.v12i1.2010. 